Article

\title{
Enhancing Biodiversity in Urban Green Space; An Exploration of the IAD Framework Applied to Ecologically Mature Trees
}

\author{
Andrew MacKenzie * (D) and Philip Gibbons \\ School of Environment and Society, Australian National University, 6201 Canberra, Australia; \\ philip.gibbons@anu.edu.au \\ * Correspondence: andrew.mackenzie@anu.edu.au; Tel.: +678-739-8599
}

Received: 9 August 2019; Accepted: 17 October 2019; Published: 22 October 2019

check for updates

\begin{abstract}
This paper investigates how institutions in urban settings potentially identify, frame, and operationalise biodiversity conservation policies. It adopts the Institutional Analysis and Development Framework (IAD) to analyse a case study regarding the retention of ecologically mature trees in urban green space in Canberra, Australia. The research investigates; what are the structural and institutional arrangements that catalyze or inhibit biodiversity conservation in urban green space? Specifically, the IAD framework is applied to explore the institutional structures and the role of key decision-makers in the conservation and management of ecologically mature trees in urban green space. Ecologically mature trees represent an exclusive habitat for many species and are key structures for conserving biodiversity in urban settings. The results suggest the application of the IAD 'rules-in-use' analysis reveals that ecologically mature trees are inconsistently managed in Canberra, leading to conflicting approaches between institutions in managing urban biodiversity. It suggests that a more structured and replicable institutional analysis will help practitioners to empirically derive a more comprehensive understanding of the roles of institutions in supporting or inhibiting biodiversity conservation in urban settings. The research finds that developers, asset managers, and other stakeholders could benefit from explicitly mapping out the defined rules, norms and strategies required to negotiate economically, socially and environmentally achievable outcomes for biodiversity conservation in urban green space.
\end{abstract}

Keywords: biodiversity conservation; open space management; IAD; landscape planning

\section{Introduction}

There have been many international calls for urban green spaces to make a greater contribution to biodiversity conservation to enhance the resilience of socio-ecological systems [1,2]. Australia, like the rest of the world, derives many of its food, medicines and consumable products from components of biodiversity. It is also an important source of ecosystem services that are beneficial to urban life such as clean water, groundwater recharge, and productive soils. Biological processes are also a primary adaptive response to changing urban environmental conditions; however, they are under threat from urbanization [3]. Australia's urban footprint is growing at more than double the average rate for developed countries [4] and is concentrated in areas of highest species diversity. Half of Australia's nationally threatened animal species reside in areas planned for urban development [5]. Thus, urbanization represents a significant threat to aspects of Australia's biodiversity. Yet, the coincidence of high species diversity within urban areas also represents an opportunity for biodiversity conservation through enhancing urban green space (biodiversity enhancement) and fostering sustainable development more broadly. 
Policy approaches to biodiversity conservation in urban areas have increasingly relied on economic instruments to demonstrate that development and conservation objectives are not incompatible [6]. To realize this relationship, urban sustainable development agendas have sought win-win outcomes through new urban governance arrangements that seek productive economic, social, and environmental outcomes [6,7]. While the aspirations for achieving such outcomes are widely promoted, the practical implications for finding such win-win solutions are elusive. In response, new approaches such as place-based land management [8], conservation planning [9] and green infrastructure governance [10] have emerged. A central principle of these approaches has been to understand the dynamic relationships between institutions in decision making and the resulting impact on the supply of ecosystem services.

Urban green space (defined here as public open space consisting of predominantly grass and trees set aside for aesthetic appreciation and informal recreation within urban areas) occupies approximately $20 \%$ of Australia's cities and towns [11]. Urban green space management is a product of complex overlapping factors including governance, finance, social capital, stakeholder motivations, individual tastes, and other institutional factors [12]. Protecting and enhancing biological processes is an important yet undervalued consideration [13]. Although an important habitat for some biota [14], the predominant regime of mowing and tidying that maintains ecologically simplistic "picturesque" park-like structures in open spaces means that urban green space lacks key habitats for several species groups [15] and ecological processes such as natural regeneration [16]. This translates to low numbers of some functional species groups as well as low numbers of species of conservation concern [17-19]. In addition, urbanization results in declining habitat values for some species over time [20,21].

How urban greenspace is managed at a range of urban scales from a metropolitan to park scale affects the landscape's capacity to support biological processes. Landscape morphology (size and distribution of green space), land-use history, and management practices all affect the extent to which urban green space can provide ecosystem services [12]. Likewise, the institutional arrangements for the financing, planning, and management of public spaces involve professionals with specialized skills (such as accountants, law makers and administrators) who do not contribute directly to biodiversity conservation [22]. As a result, these decision-makers unintentionally distance themselves from the ecosystems they influence through the decision-making process. Therefore, despite potential environmental, economic, and social benefits, the practice of ecological restoration is not applied widely in urban green space management [20].

\subsection{Ecologically Mature Trees in Canberra, Australia}

Ecologically mature trees in Australian cities, often several centuries old, represent an exclusive habitat for many species and are key structures for conserving species in urban settings [23]. Yet recent research has indicated that ecologically mature trees are declining within intensively-managed urban and peri-urban landscapes [14]. Although an important habitat for some biota, the predominant regime of removing ecologically mature trees means that urban green space lacks key habitats for several species groups and ecological processes such as interspecies competition and natural regeneration which are critical factors influencing biological processes in urban settings. Despite many international calls for urban green spaces to make a greater contribution to biodiversity conservation (see for example the New Urban Agenda adopted at Habitat III, the 2016 United Nations Conference on Housing and Sustainable Urban Development), these trees are often subject to removal orders because they are perceived as unsightly and unsafe. As a result, urban green space in Canberra in the Australian Capital Territory (ACT) supports significantly fewer habitats with nesting hollows, dead trees, logs, and ecosystem regeneration compared with adjacent nature reserves [14]. This translates to low numbers of some species' functional groups and species of conservation concern as well as declining habitat values for some species through time.

Preserving ecologically mature trees within urban green spaces may also achieve other socio-economic objectives. For example, reinstating ecological processes may reduce the costs of mowing, weed control, and replacement planting. Natural environments created by ecological 
restoration will also provide greater opportunity for community engagement through volunteerism and citizen science [12]. Community engagement with biodiversity conservation not only creates and strengthens a sense of wellbeing but also potentially reduces maintenance costs through volunteerism. It should be noted however that voluntary mechanisms should not be used in isolation except where private and public interests substantially coincide [3]. Despite the apparent biodiversity benefits, institutional resistance to retaining ecologically mature trees remains a significant problem. As a result, the economic and social benefits of retaining ecologically mature trees are not applied widely in urban green space management policies and practices. Key barriers relate to hazards associated with the accumulation of fire-fuels, falling limbs, and pest control. Ecologically mature trees do not present an unacceptable risk; however perceptions of risk that lack supporting empirical evidence reinforce assumptions that the retention of these trees is incompatible with community expectations of how urban green spaces should be safely managed.

\subsection{The Barriers to Enhancing Urban Biodiversity}

A key knowledge gap exists in understanding the mechanisms that underpin peoples' response to natural features in urban green space, particularly in Australia where natural features often look very different from traditional European style picturesque parks. This cultural attitude has historically dictated management practices that have, in turn, reinforced cultural norms about the expected appearance of urban green space. From a biodiversity conservation perspective, these practices are detrimental. The major management activities that undermine efforts to support biodiverse environments in urban areas include maintenance of grasses using turf management techniques, including reducing species diversity through regular mowing and the use of broad-spectrum pesticides and herbicides [12]. In addition, the removal of habitat, including the collection of logs, branches and leaf litter and the removal of senescent and dead trees that are ecologically significant results in the simplification of habitat structure.

Compounding these entrenched practices is the lack of awareness of biodiversity values in adapting greenspace management practices. As a result, little consideration is given to how green spaces at a range of scales can support or inhibit biological processes across a metropolitan area [12] and this lack of awareness inhibits innovation in management practices. For example, urban green spaces in greenfield urban estate developments are typically established by a developer and transferred to the government for ongoing management. However, reluctance on the part of municipal authorities to encourage innovation (e.g., due to inflexible internal processes or a lack of resources for evaluating and understanding risks and benefits of alternatives) makes it difficult for developers to innovate due to design constraints imposed by the asset manager. Likewise, the economic implications of new management approaches are poorly researched, particularly when considering how the long term economic benefits can potentially offset the short term costs of establishment. Similarly, the benefits of adopting alternative management practices alongside good community consultation processes can potentially lead to private individuals accepting and mimicking such approaches in their own gardens and bringing wider scale conservation benefits [20]. These conflicting agendas and barriers to change cannot be addressed as single-issue policy responses. For this reason, an institutional framework for unpacking the fragmented nature of decision-making is needed.

\subsection{Applying the IAD Framework}

Research of ecosystems tends to concentrate on ecosystem functions resulting from interacting factors rather than exploring institutional and socioeconomic drivers of ecological change [12]. However, more recently, research has been undertaken to develop tools designed to evaluate human-environment systems and how they interact in urban socio-ecological systems. For example, ecological assessments of species diversity and abundance can include surveys to understand how actions and decisions by individuals and institutions at different scales affect urban biological processes [24]. More recently, 
multidisciplinary research has focused on the study of urban ecosystems as nested parts of broader socio-ecological systems and how these biophysical and social systems interact.

Applying a framework presents an opportunity to develop strategies that take into consideration the nature of urban institutions and the interactions with urban actors that affect biological processes in urban settings [24]. A framework helps the researchers to structure their thinking about a system and provides a scaffold for developing theories and models to examine the research question [25,26]. Nagendra and Ostrom [27] argue that understanding the interactions between actors at different levels of government contributes a more nuanced understanding of the governance arrangements in the management of common-pool resources such as biological processes. This approach emphasises the need to pay attention to the functional characteristics of policy instruments rather than simply adopting a comparative analysis and using economic instruments to determine success [28].

The Institutional Analysis and Development (IAD) is an established framework that is used to explore a wide range of human behaviour and interactions within socio-ecological systems $[25,26]$. Rather than adopting a conventional cost-benefit economic analysis to calculate the optimal policy solution to determine the costs and benefits derived from biodiversity conservation, IAD explores how biodiversity values inform decision making within institutions [27]. Pursuing a policy analysis of the case study in question requires a concise definition or characterisation of the institutions involved. Institutions include different groups engaging in different systems of governance to address problems democratically [26]. Academic interpretations take a broader definition to incorporate informal, as well as formal, associations that are not necessarily easily defined as entities per se [28]. Consequently, scholarly inquiry tends to be more concerned about the institutional or governing dynamics that characterise institutions rather than the impacts of decision making on ecosystem services. This research adopts the IAD as a framework to explore the role of key stakeholders and how decisions are made within the decision-making framework for managing ecologically mature trees in Canberra, Australia's national capital.

The IAD framework provides a consistent language and a systematic process that allows for a comparative analysis of how stakeholders participate in a biodiversity conservation decision-making space $[26,28]$. From a research perspective, the IAD framework helps to generate questions that need to be addressed [26]. In this case, the researchers considered the following: what are the socio-political structural and institutional arrangements that catalyse or inhibit biodiversity conservation and enhancement in urban green space? From a policy perspective, the IAD framework helps to explain stakeholder interactions and decisions in the context of a number of factors. These include the physical or material nature of the biological processes in question, the attributes of the community, and the rules that create incentives and constraints upon decision-makers [27]. Likewise, the IAD framework is a useful strategy for cross-disciplinary teams examining a policy issue as it provides a shared language and a reference for case study design. Such an approach can also translate into more codified tools for implementation such as enforceable guidelines and regulations, or less formal codes such as handbooks and instruction manuals [28].

\section{Materials and Methods}

A more detailed analysis of the institutions affecting urban biological processes helps the researcher understand how individuals and organisations are incentivised to conserve or destroy habitat diversity in urban settings. The IAD provides the researcher with a systematic framework to identify and analyse these institutional interactions that directly impact landscape management practices that affect the production of biological processes. From this perspective, institutions are a key variable in determining how to preserve and enhance urban ecological systems in urban planning and management. Management of urban biodiversity, in this case, can be examined as an institutional question [25], distinct from a broader social inquiry, because institutions influence the incentives of decision-makers through rules and regulations, thereby affecting individuals' choices and actions [26]. Rules are the central tenet of the IAD's institutional analysis tool. Broadly speaking, three categories of rules exist. 
These include those that denote regulations (rules), a set of instructions (strategies), or guidelines and conventions (norms).

The IAD framework was chosen to analyse the research question due to its polycentric nature [28]. In other words, the IAD model establishes a framework that deals with multiple institutional levels, different jurisdictional arrangements, and stakeholder interests across a range of sectors [25]. The IAD rules-in-use taxonomy was applied to analyse the functional characteristics of the formal and informal management instruments and the role of key decision-makers' actions relating to the research question [28]. The aim of applying this approach was twofold. The first was to determine the applicability of the IAD model in the context of the research question. The second was to provide a case for regulatory reform to stakeholders, and to critically review the norms and conventions around the management of ecologically mature trees in Canberra. The research is the initial phase of a larger project seeking to improve biodiversity conservation in urban settings. This stage of the research undertook a desktop review of regulations, policies, and plans related to the conservation and management of ecologically mature trees in the case study. Later stages of the research involve surveying and analysing patterns of species and functional diversity in response to the different landscape design treatments, along with surveys of stakeholder attitudes towards urban green space values [24].

In adopting the IAD framework, the formal rules-in-use analysis [26] potentially allows for a wider interrogation of stakeholder attitudes to biodiversity conservation and the deployment of both regulatory and informal instruments to manage urban green space. Such an approach provides a diagnosis of the functional characteristics of policy instruments but does not explain the interactions between these characteristics [27]. None the less, by describing the institutional structures that influence the management of urban biological processes, decision-makers can better understand how biodiversity conservation is managed in an urban context.

\section{Results: The Application of IAD to Conserving Ecologically Mature Trees}

Figure 1 applies Ostrom's IAD framework to identify the nature of the stakeholder interaction within a range of environmental, social, and regulatory variables. According to Ostrom [28], action situations are social spaces where interactions, exchanges, problem-solving, and contests for power occur. In relation to the case study, the action arena (referred to, for the purposes of this research, as the biodiversity enhancement decision space) is influenced by exogenous variables including current physical attributes of urban green space, social attitudes towards the landscape, and institutional arrangements affecting landscape management [29]. The action situation is the unfolding relationship between actors and their approach to decision making concerning biological processes through the development and management of urban green spaces. Empirically the impact of the action situation on biodiversity outcomes can be evaluated by measuring how many ecologically mature trees are retained, how they are managed (e.g., pruning and limb removal), and how the surrounding open space supports a structurally complex ecosystem through landscape treatments and maintenance practices [30,31]. 


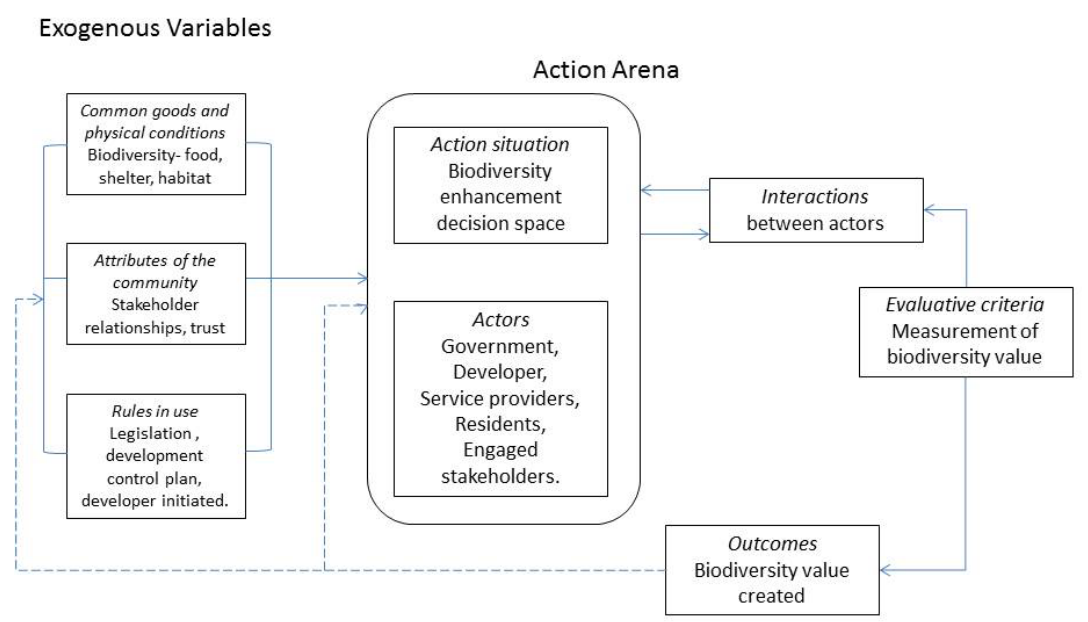

Figure 1. Application of the IAD (Institutional Analysis and Development) framework and establishes the nature of the relationships between institutions affecting the management of biodiversity in an urban setting. Adapted from Ostrom [32].

In applying the rules-in-use to the action situation, the decision spaces are identified where ecologically mature trees can potentially be retained and managed in a way that maximises the biodiversity conservation benefits though enhancement of the urban green spaces that accommodate these trees [33]. The taxonomy of rules-in-use, as described by Ostrom [34], includes boundary, position, choice, information, scope, aggregation, and pay off rules. Boundary rules specify an actor's eligibility to act and how they are to be chosen to hold a decision-making position. Position rules assign actions at particular decision points and how certain actors can enforce each decision. Choice rules specify which actions are assigned to an actor in a position. Information rules specify channels of communication among actors and what information must, may, or must not be shared. Scope rules specify the outcomes that could be affected. Aggregation rules specify how the decisions of actors are to be mapped to determine intermediate or final outcomes, and payoff rules specify how benefits and costs are to be distributed [32,33].

In applying the rules-in-use taxonomy (Figure 2), the role of the ACT government in modifying legislation is pertinent (see, for example, boundary rules, information rules, and aggregation rules). Yet, the role of the motivated developer to improve biodiversity outcomes points to a need for more flexibility in enforcing regulations and management protocols by the government asset managers (see, for example, aggregation, choice and payoff rules). This finding, resulting from this analysis, points to the need for a critical review of internal government processes in the case study; in particular, the application of defined rules interpreted differently by agencies operating under the same legislation. 


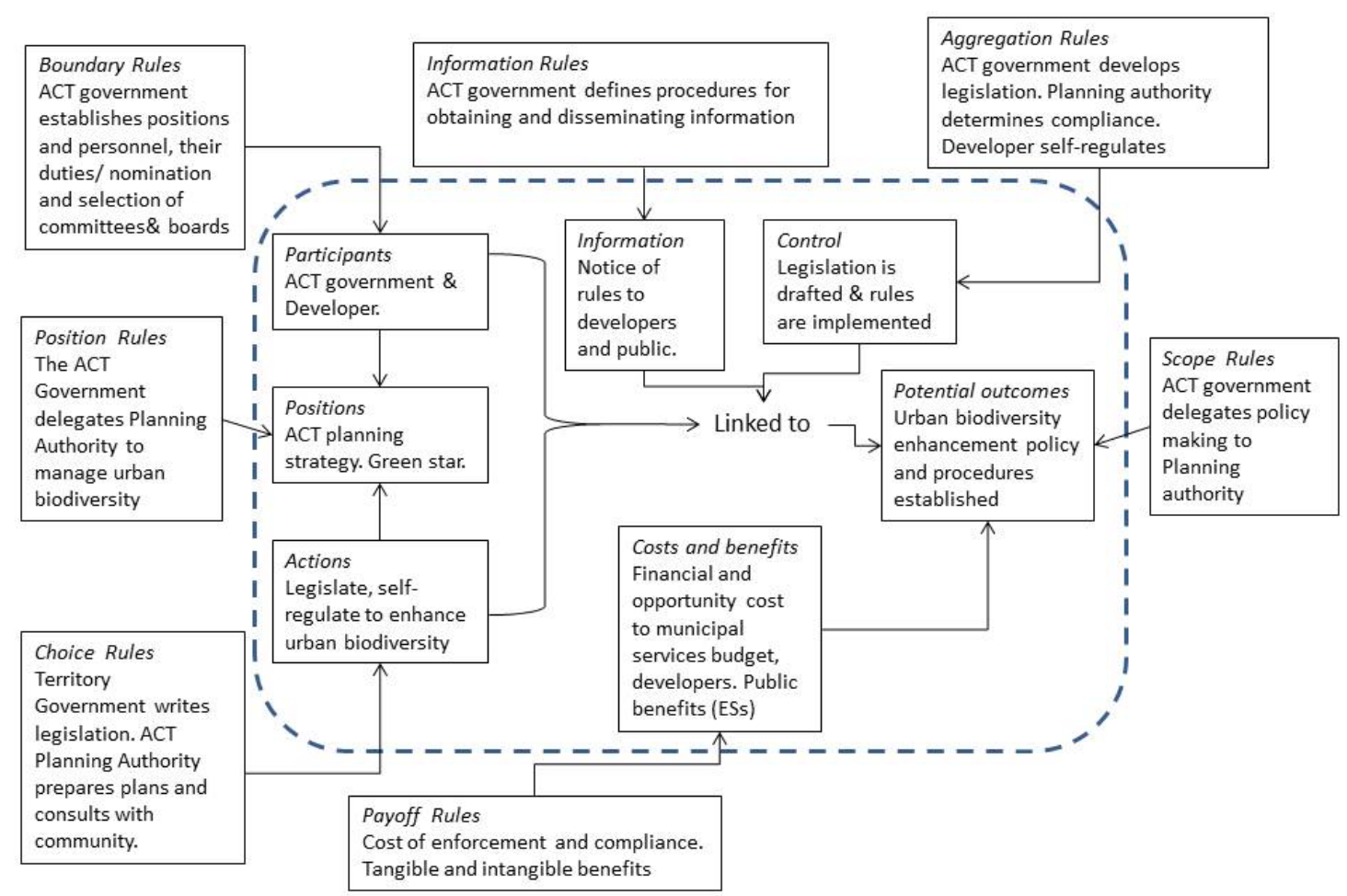

Figure 2. The IAD rules-in-use is applied to ecologically mature trees and map the institutions related to operational level management of urban open space. Adapted from Ostrom [32].

\section{Discussion}

The protection and management of ecologically mature trees in the ACT is defined formally in the Territory's tree protection legislation. All regulated trees on privately leased land and public green spaces are covered by this legislation. Regulated trees are classified according to minimum height, canopy circumference, and trunk diameter. Other legislation that interacts with the tree protection legislation includes regulations for planning and development and nature conservation. While the objectives for tree protection are described in the tree protection legislation, all three instruments guide decision-makers about how trees are to be maintained, listed for protection, or removed. For example, the Planning and Development Act (2007) describes the preparation of tree management plans for certain developments, and the Nature Conservation Act (2014) describes offences related to the damage of native trees on unleased and leased territory land. The enforcement of these legislative instruments is delegated to relevant operational branches of municipal departments. Importantly, specific powers reside with the ACT Conservator of Flora and Fauna with regard to both legislative instruments. The operational rules are defined in legislation and reviewed based on expert advice from within the responsible departments and external experts providing evidence from a range of industry and community stakeholders. Ultimately, the operational rules are adapted and updated through a legislative review or periodic technical review of regulations that do not require parliamentary approval. The opportunity exists for the research team to be more targeted in the presentation of evidence collected in later phases of the project to argue the case for legislative changes to the operational rules that guide the conservator's decisions.

The action situation described in Figure 1 as the 'biodiversity enhancement decision space' is intended to produce optimal outcomes. However, in practice, the potential exists or is indeed likely for sub-optimal outcomes given the lack of critical analysis of exogenous variables (common goods, community attributes, and rules-in-use) and the relationships to the action arena in decision-making (the actors and their interactions in relation to the action situation). This results in a disconnect between the institutions impacting the inner workings of an action situation and the policies regarding biodiversity 
conservation with respect to the management of ecologically mature trees [22]. This disconnection results in part because the ACT government designates the management of ecologically mature trees in urban green spaces to the city services department, while nature conservation responsibilities are designated to the planning and sustainable development department. The conservator, on the other hand, oversees policies, programs, and plans for both nature conservation under the Nature Conservation Act (2014) and provides operational discretion on the removal of regulated trees under the Tree Protection Act (2005) and the Planning and Development Act (2007). Therefore, the conservator has considerable decision-making powers to navigate best practice for green space management by taking into consideration the objectives of the overlapping legislation.

From a nature conservation perspective, the Conservator is guided by advisory bodies such as the Natural Resource Management Council and the ACT Scientific Committee. In relation to decisions regarding the removal or management of trees, the Conservator is constrained by operational rules defined in the legislation and guided by a Tree Advisory Panel established under the Tree Protection Act (2005). Unintended outcomes may result from the actions of these departments (institutions) that are meant to aid in the management of natural resources to foster sustainable development. The perverse outcome described here results from causal links emerging between the actions of different institutions without a structured institutional analysis into the barriers that inhibit biological processes in urban green spaces. This is an outcome of the biodiversity enhancement decision space (the action situation) being poorly articulated through operational rules. This results in the urban forest managers, defined by position rules (their program of activity is guided by the conservator), removing ecologically mature trees (with a permit) and replanting with inappropriate species for achieving biodiversity outcomes (defined by choice rules). Yet the main actors, including property owners, developers and asset managers (boundary rules) generally agree on the benefits of enhancing biological processes if it results in enhanced social and economic benefits (payoff rules).

The definition of ecologically significant trees is often unclear to the public, as is the role of property owners in their management (i.e., who makes decisions about the status of the trees under legislation) [24]. In this case study, the objective of the Tree Protection Act (2005) is to protect individual trees in urban green spaces that have exceptional qualities because of their natural values and to protect urban forest values that may be at risk from incremental loss or degradation. However, the definition of individual trees of exceptional natural qualities and the urban forest values that need to be protected are not specified. Therefore the presence or absence of information rules affects the management of ecologically mature trees and in turn the production of biological processes. In addition, when the responsibility for the protection natural values is claimed by one public agency (e.g., environment protection) but management responsibility of the trees providing those values lies with the private sector (developers, property owners) or another department (asset management and municipal services), confusion and misunderstanding arises about which entity is responsible for managing specific ecosystem services provided thus indicating the need to define aggregation rules. In the case of new urban developments, decisions about the value of ecologically mature trees are reconciled against the opportunity cost of building on the land occupied by the trees and their immediate surrounds. In the case of asset managers, the costs of tree and park maintenance are balanced against the potential biodiversity values. In other words, payoff rules are imposed and transactional costs are incurred, including time and resources spent redesigning policies, plans, maintenance manuals, and design guidelines.

Even when biodiversity values and the role of ecologically mature trees are understood, management decisions, including decisions to remove trees, are affected by other factors. These include the extent of monitoring and evaluation of biodiversity benefits, and how this information is communicated to the public as well as asset managers. In addition, agencies are often understaffed leading to poor knowledge translation and resistance to novel approaches and innovative practices. Similarly, uninformed or disinterested private individuals may exert political pressure on department heads to persist with conventional practices that are damaging to habitat protection and akin to 
'cleaning up' the landscape [12]. In some cases, sanctions for the illegal removal of ecologically mature trees are inadequate or not enforced. In this case, the costs of retention exceeds the costs of compliance and the payoff of breaking the rules is vindicated in the mind of the proponents [23].

There are many other action situations that contribute to the protection of urban biodiversity (e.g., protecting waterways and grasslands) and the retention and management of ecologically mature trees to improve biodiversity outcomes is just one. However, as demonstrated through this example, institutional gaps can arise from a range of rules-in-use that structure the action situation (the biodiversity enhancement decision space). These shortcomings can be mitigated by understanding the instances of incongruence between the policies for biodiversity conservation and operational outcomes. Further analysis is needed to determine the relevant variables influencing the likelihood of appropriate actions being adopted in the management of ecologically mature trees to enhance urban biodiversity [22].

This analysis of the IAD framework does not find that residents, developers, and government agencies are incapable of re-conceptualising the role of ecologically mature trees and adapting management practices to reflect biodiversity conservation objectives. In some instances, developers in the ACT have voluntarily retained ecologically mature trees in an attempt to mitigate the impact of urban development on biodiversity values in order to enhance their reputation to an environmentally aware local community. With more codified information rules about the definition of ecologically mature trees and the benefits to biodiversity values, incentives and sanctions may be adjusted to allow for improved collective management of ecologically mature trees across Canberra's diverse urban forest. Decision-makers in urban areas can appreciate from the analysis of natural resource management in rural areas that there is no specific governance regime that is more successful than any other in achieving desired outcomes [33]. It is the local context, the cultural and social relationships, biophysical characteristics and political characteristics that provide the basis for appropriate governance regimes for resource management [34].

\section{Conclusions}

This paper argues that a detailed institutional analysis based on the IAD framework can be applied to examine ways to enhance biological processes in urban settings. However such empirical analysis is yet to be widely tested in the management of urban ecosystem services such as biological processes. This is in part due to a lack of clarity concerning how institutions are classified, analysed and operationalised within a governance framework. Identifying the institutions that define the rules, strategies, and conventions and recognising the nested nature of operational decisions in achieving desirable management objectives should help decision-makers to better align policy objectives and practices for enhancing urban biodiversity.

While the IAD has been used widely in the study of broad socio-ecological systems such as fisheries management and other common-pool resources, it has not been commonly applied to urban scenarios due to complex overlapping factors inherent in cities. The application of the IAD in this context serves two purposes. First, it establishes the applicability and generalisability of the IAD model in exploring institutional dynamics affecting the production of ecosystem services in urban settings. Secondly, the IAD framework provides an empirically sound method for identifying and analysing specific instances where changes to institutional arrangements (through changes to legislation, practices, and conventions) can lead to improved practices that are otherwise elusive to decision-makers who genuinely wish to achieve better urban green space management outcomes.

Author Contributions: A.M. was the principal author. A.M. contributed the literature review concerning the institutional analysis, governance and open space management. A.M. developed the methodology and applied to the case study. P.G. developed the case study and literature review concerning biological processes, ecologically mature trees and management of urban biodiversity.

Funding: This research received no external funding.

Acknowledgments: The authors would like to acknowledge the time given by the Ginninderry Group, Canberra. 
Conflicts of Interest: The authors declare no conflict of interest.

\section{References}

1. Miller, J.R.; Hobbs, R. Conservation where people live and work. Conserv. Biol. 2002, 16, 330-337. [CrossRef]

2. Dearborn, D.C.; Kark, S. Motivations for conserving urban biodiversity. Conserv. Biol. 2010, 24, 432-440. [CrossRef] [PubMed]

3. Gunningham, N.; Young, M.D. Toward optimal environmental policy: The case of biodiversity conservation. Ecol. LQ 1997, 24, 243.

4. Ives, C.D.; Lentini, P.E.; Threlfall, C.G.; Ikin, K.; Shanahan, D.F.; Garrard, G.E.; Bekessy, S.A.; Fuller, R.A.; Mumaw, L.; Rayner, L.; et al. Cities are hotspots for threatened species. Glob. Ecol. Biogeogr. 2016, 25, 117-126. [CrossRef]

5. Commonwealth of Australia. State of Australian Cities 2014-2015; Department of Infrastructure and Regional Development: Canberra, Australia, 2015.

6. Rode, J.; Wittmer, H.; Emerton, L.; Schröter-Schlaack, C. 'Ecosystem service opportunities': A Practice-Oriented framework for identifying economic instruments to enhance biodiversity and human livelihoods. J. Nat. Conserv. 2016, 33, 35-47. [CrossRef]

7. Bulkeley, H.; Betsill, M. Rethinking sustainable cities: Multilevel governance and the 'urban' politics of climate change. Environ. Politics 2005, 14, 42-63. [CrossRef]

8. Brown, G.; de Bie, K.; Weber, D. Identifying public land stakeholder perspectives for implementing Place-Based land management. Landsc. Urban Plan. 2015, 139, 1-15. [CrossRef]

9. Bekessy, S.A.; White, M.; Gordon, A.; Moilanen, A.; McCarthy, M.A.; Wintle, B.A. Transparent planning for biodiversity and development in the urban fringe. Landsc. Urban Plan. 2012, 108, 140-149. [CrossRef]

10. Young, R.; McPherson, E. Governing metropolitan green infrastructure in the United States. Landsc. Urban Plan. 2013, 109, 199-223. [CrossRef]

11. Timperio, A.; Ball, K.; Salmon, J.; Roberts, R.; Crawford, D. Is availability of public open space equitable across areas? Health Place 2007, 13, 335-3405. [CrossRef]

12. Aronson, M.F.; Lepczyk, C.A.; Evans, K.L.; Goddard, M.A.; Lerman, S.B.; MacIvor, J.S.; Vargo, T. Biodiversity in the city: Key challenges for urban green space management. Front. Ecol. Environ. 2017, 15, 189-196. [CrossRef]

13. Ikin, K.; Le Roux, D.S.; Rayner, L.; Villaseñor, N.R.; Eyles, K.; Gibbons, P.; Manning, A.D.; Lindenmayer, D.B. Key lessons for achieving Biodiversity-Sensitive cities and towns. Ecol. Manag. Restor. 2015, 16, 206-214. [CrossRef]

14. Le Roux, D.S.; Ikin, K.; Lindenmayer, D.B.; Blanchard, W.; Manning, A.D.; Gibbons, P. Reduced availability of habitat structures in urban landscapes: Implications for policy and practice. Landsc. Urban Plan. 2014, 125, 57-64. [CrossRef]

15. Hobbs, E.R. Species richness of urban forest patches and implications for urban landscape diversity. Landsc. Ecol. 1988, 1, 141. [CrossRef]

16. Stagoll, K.; Manning, A.D.; Knight, E.; Fischer, J.; Lindenmayer, D.B. Using Bird-Habitat relationships to inform urban planning. Landsc. Urban Plan. 2010, 98, 13-25. [CrossRef]

17. Wong, D.; Jones, S.; Osborne, W.; Brown, G.; Robertson, P.; Michael, D.; Kay, G. The life history and ecology of the Pink-Tailed Worm-lizard Aprasia parapulchella Kluge-A review. Aust. Zool. 2011, 35, 927-940. [CrossRef]

18. Rayner, L. Avifauna and urban encroachment in time and space. Divers. Distrib. 2015, 21, 428-440. [CrossRef]

19. Hunter, M.R.; Hunter, M.D. Designing for conservation of insects in the built environment. Insect Conserv. Divers. 2008, 1, 189-196. [CrossRef]

20. Stagoll, K.; Lindenmayer, D.B.; Knight, E.; Fischer, J.; Manning, A.D. Large trees are keystone structures in urban parks. Conserv. Lett. 2012, 5, 115-122. [CrossRef]

21. Francis, R.; Chadwick, M. Urban Ecosystems: Understanding the Urban Environment; Routledge: London, UK, 2013.

22. Le Roux, D.S.; Ikin, K.; Lindenmayer, D.B.; Manning, A.D.; Gibbons, P. The future of large old trees in urban landscapes. PLoS ONE 2014, 9, e99403. [CrossRef] 
23. Plant, R.; Boydell, S.; Prior, J.; Chong, J.; Lederwasch, A. From liability to opportunity: An institutional approach towards Value-Based land remediation. Environ. Plan. C Politics Space 2017, 35, 197-220. [CrossRef]

24. Mincey, S.K.; Hutten, M.; Fischer, B.C.; Evans, T.P.; Stewart, S.I.; Vogt, J.M. Structuring institutional analysis for urban ecosystems: A key to sustainable urban forest management. Urban Ecosyst. 2013, 16, 553-571. [CrossRef]

25. Ostrom, E. Governing the Commons: The Evolution of Institutions for Collective Action; Cambridge University Press: Cambridge, UK, 1990.

26. Ostrom, E. Background on the institutional analysis and development framework. Policy Stud. J. 2011, 39, 7-27. [CrossRef]

27. Nagendra, H.; Ostrom, E. Polycentric governance of multifunctional forested landscapes. Int. J. Commons 2012, 6, 104-133. [CrossRef]

28. Ostrom, E. Beyond markets and states: Polycentric governance of complex economic systems. Am. Econ. Rev. 2010, 100, 641-672. [CrossRef]

29. Gibson-Roy, P. Expanding horizons for herbaceous ecosystem restoration: The Grassy Groundcover Restoration Project. Ecol. Manag. Restor. 2010, 11, 176-186. [CrossRef]

30. McGinnis, M.D. An introduction to IAD and the language of the Ostrom workshop: A simple guide to a complex framework. Policy Stud. J. 2011, 39. [CrossRef]

31. Munro, N.T. Faunal response to revegetation in agricultural areas of Australia: A review. Ecol. Manag. Restor. 2007, 8, 199-207. [CrossRef]

32. Ostrom, E. Understanding Institutional Diversity; Princeton University Press: Princeton, NJ, USA, 2005.

33. Barton, D.N.; Benavides, K.; Chacon-Cascante, A.; Le Coq, J.F.; Quiros, M.M.; Porras, I.; Ring, I. Payments for Ecosystem Services as a Policy Mix: Demonstrating the institutional analysis and development framework on conservation policy instruments. Environ. Policy Gov. 2017, 27, 404-421. [CrossRef]

34. Moran, E. Human-Environment interactions in forest ecosystems: An introduction. In Seeing the Forest and the Trees: Human Interactions in Forest Ecosystems; Moran, E., Ostrom, E., Eds.; MIT Press: Cambridge, MA, USA, 2005; pp. 3-22.

(C) 2019 by the authors. Licensee MDPI, Basel, Switzerland. This article is an open access article distributed under the terms and conditions of the Creative Commons Attribution (CC BY) license (http://creativecommons.org/licenses/by/4.0/). 